\title{
Rapid method for detecting monoclonality in B cell lymphoma in lymph node aspirates using the polymerase chain reaction
}

\author{
J H Wan, P J Sykes, S R Orell, A A Morley
}

\begin{abstract}
Aims: To use the polymerase chain reaction to detect monoclonality at the immunoglobulin heavy chain gene locus in cells derived from lymph node aspirates.

Methods: A nested two-stage polymerase chain reaction (PCR) for the $V D$, region of the immunoglobulin heavy chain gene was used to detect monoclonality. The total number of cells available for diagnosis by PCR in lymph node aspirates was between $10^{4}$ and $10^{5}$.

Results: A monoclonal band was detected in 21 of 25 malignant B-lymphomas. The other four specimens gave polyclonal bands. Specimens from reactive lymph nodes produced polyclonal bands in 14 cases, no product in two cases, and one specimen gave two monoclonal bands. Polyclonal bands were obtained for three Hodgkin's lymphoma samples and five metastatic carcinomas. Four metastatic carcinoma samples gave no amplification.

Conclusions: Detection of monoclonality in a cell population is strongly suggestive of malignant disease. The simple PCR method presented here should complement conventional cytological and immunological methods for diagnosis of malignancy by lymph node aspirates.
\end{abstract}

Fine needle aspiration of lymph nodes is widely used in clinical cytopathology for diagnosis of lymphoma, secondary carcinoma, and reactive disorders. Problems in the amount and quality of material in aspirates and the inherent difficulties in diagnosis of disorders of lymph nodes place limitations on the value of aspiration as currently performed. ${ }^{1}$ Additional methods for study of aspirated material could help to overcome these limitations.

Although not diagnostic, monoclonality of a cell population suggests the presence of malignancy and for this reason detection of monoclonal rearrangements of the immunoglobulin or $\mathrm{T}$ cell receptor genes has proved to be a valuable marker for malignancy in haematological disorders. The conventional technique of Southern blotting for detection of gene rearrangement requires an amount of DNA not usually obtainable from a lymph node aspirate. Recently Trainor et al and Wan et al used the polymerase chain reaction (PCR) to develop techniques for detection of monoclonality in lymphoproliferative disorders using fresh or frozen samples of blood, bone marrow, lymph node, and paraffin wax embedded tissue sections. ${ }^{23}$ The extreme sensitivity of the PCR should enable monoclonality to be detected in a small number of target cells and thus in a lymph node aspirate. We describe the use of the PCR to study lymph node aspirates in a variety of neoplastic and non-neoplastic conditions of lymph nodes.

\section{Methods}

Patients and cell lines

Lymph node aspirates were obtained from 25 patients with a diagnosis of non-Hodgkin's lymphoma (NHL). Histological reports and/or sections were available in 22 and results of immunophenotyping in four. The histological subtypes (Kiel classification) were centrocytic/ centroblastic $(n=8)$, centroblastic $(n=7)$, centrocytic $(n=5)$, immunoblastic $(n=1)$, and lymphoblastic $(n=1)$. The results in the four patients who had immunophenotyping showed a B cell origin in three and a probable $T$ cell origin in one, who was classified as centroblastic on morphology. Lymph node aspirates were obtained from three patients with Hodgkin's lymphoma, 17 cases with nonneoplastic reactive lymph node enlargement, and nine patients with metastatic non-lymphoid neoplasm (including squamous carcinoma, undifferentiated carcinoma, small cell carcinoma, melanoma, adenocarcinoma, and prostate carcinoma). All of these aspirate samples had been studied and classified as Hodgkin's lymphoma, reactive proliferation, or metastatic carcinoma by routine cytopathology. The aspirate samples were obtained from the Department of Histopathology, Flinders Medical Centre and Clinpath Laboratories, Adelaide.

In addition, human pre B-lymphocyte Nalm6 and myeloma U266 cell lines were used to determine the sensitivity of the PCR. ${ }^{45}$ Normal human peripheral blood lymphocytes were isolated from whole blood by Ficoll gradient centrifugation.

\section{Method of DNA extraction}

Aspirates were received in Hanks's solution and stored at $4^{\circ} \mathrm{C}$ on arrival. The number of cells present in the lymph node aspirate was determined using a haemocytometer and was between $1 \times 10^{4}$ to $1 \times 10^{5}$ total cells. The method of DNA extraction followed that of Higuchi $^{6}$ with some modification. Aspirate 
samples were centrifuged at $6500 \mathrm{rev} / \mathrm{min}$ for two minutes, the supernatant removed, and the pellet washed with $0.5-1.0 \mathrm{ml}$ saline. The centrifugation step was repeated, the supernatant removed, and the cells resuspended in 1 $\mathrm{ml}$ lysis buffer (0.32 $\mathrm{M}$ sucrose, $10 \mathrm{mM}$ Tris$\mathrm{HCl}$ (pH 7.5), $5 \mathrm{mM} \mathrm{MgCl}, 1 \%$ Triton X100). After centrifuging at $6500 \mathrm{rev} / \mathrm{min}$ for two minutes, the supernatant was removed immediately and PCR extraction buffer was added to a final concentration of $10^{4}$ cells $/ 10 \mu \mathrm{l}$ PCR extraction buffer $(50 \mathrm{mM} \mathrm{KCl}, 10 \mathrm{mM}$ Tris- $\mathrm{HCl} \mathrm{pH} 8 \cdot 3,0.1 \mathrm{mg} / \mathrm{ml}$ gelatin, $0.45 \%$ Nonidet P-40, 0.45\% Tween 20) and $6 \mu$ l of 1 $\mathrm{mg} / \mathrm{ml}$ proteinase $\mathrm{K}$ was added per $100 \mu \mathrm{l}$ extraction buffer. The samples were incubated at $60^{\circ} \mathrm{C}$ overnight. Extracts were then incubated at $95^{\circ} \mathrm{C}$ for ten minutes to inactivate the proteinase $\mathrm{K}$. As the DNA source for PCR amplification $10 \mu \mathrm{l}$ extract was used. Each sample had a control consisting of lysis and extraction buffer which was subjected to the same procedure.

\section{Polymerase chain reaction}

Primers were synthesized on an Applied Biosystems automated synthesizer (model 371). The primers used for the $3^{\prime}$ end of the J region and $3^{\prime}$ end of the $V$ region of the human immunoglobulin heavy chain genes have been described. $^{78}$ Their sequences are: FR3A, 5'ACACG G[C/T][G/C]TGTATT ACTGT3'; LJH, 5'TGAGGAGACGGTGACC 3'; VLJH, ' 5'GTGACCAGGGT[A/G/C/T] CCTTGGCCCCAG 3'

PCR was performed in a thermal cycler (Perkin Elmer Cetus). The procedure for nested PCR followed that of Wan et $^{3} \mathrm{l}^{3}$ with some modifications. The PCR reaction mixture consisted of $0 \cdot 1 \mu \mathrm{g}$ FR3A, $0 \cdot 16 \mu \mathrm{g} \mathrm{LJH}$, or $0.25 \mu \mathrm{g} \mathrm{VLJH}$ primer, 0.35 units of Taq polymerase (Amplitaq, Cetus), $0 \cdot 1 \mathrm{mM}$ of each dNTP, 67 $\mathrm{mM}$ Tris- $\mathrm{HCl} \mathrm{pH} 8.8,16.6 \mathrm{mM}\left(\mathrm{NH}_{4}\right)_{2} \mathrm{SO}_{4}$, $2.0 \mathrm{mM} \mathrm{MgCl}_{2}, 10 \mathrm{mM} \beta$-mercaptoethanol, $200 \mu \mathrm{g} / \mathrm{ml}$ gelatin, and DNA template in a total volume of $25 \mu \mathrm{l}$.

The sample was denatured for five minutes at $94^{\circ} \mathrm{C}$, and 30 cycles were performed for one minute at $72^{\circ} \mathrm{C}$ (extension), one minute at $55^{\circ} \mathrm{C}$ (annealing) and one minue at $94^{\circ} \mathrm{C}$ (denaturation). After 30 cycles, a final extension step of 20 minutes at $72^{\circ} \mathrm{C}$ was performed. The

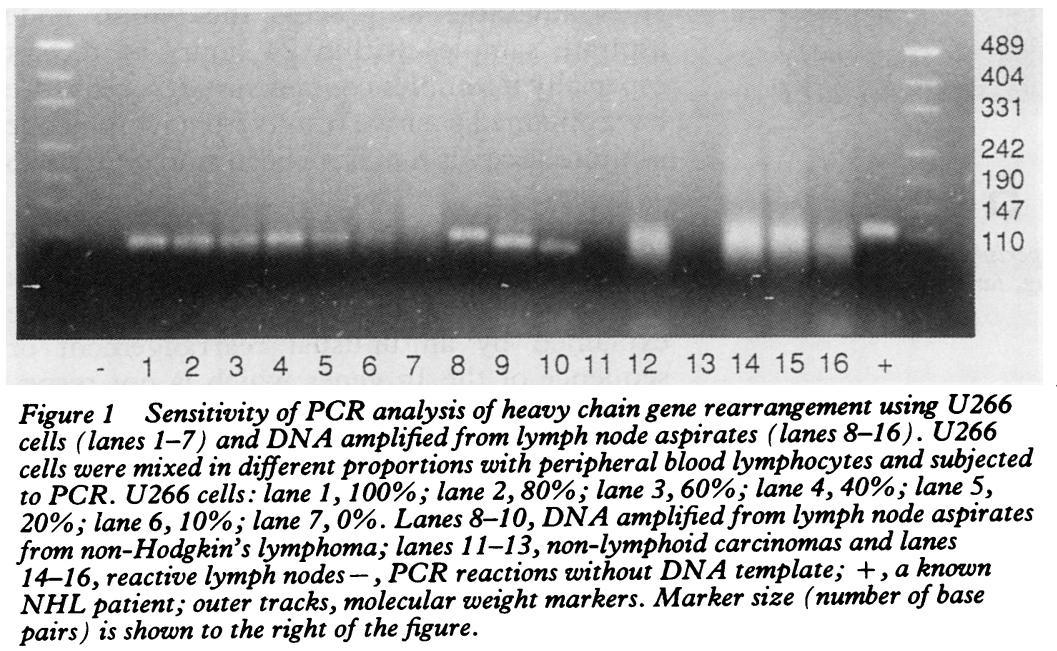

amplified sample was diluted 1000 -fold in water and added to a fresh PCR mix, followed by a second round amplification of 20 cycles.

FR3A and LJH primers were used in the first round of 30 cycles and FR3A and VLJH in a second round of 20 cycles. Five $\mu$ l of PCR amplified material from the second round were electrophoresed in $2 \%$ agarose gels with 0.5 $\mu \mathrm{g} / \mathrm{ml}$ ethidium bromide in $0.5 \times \mathrm{TBE}$ buffer (44.5 mM Tris- $\mathrm{HCl}, 44.5 \mathrm{mM}$ boric acid, 1 $\mathrm{mM}$ ethylenediamine tetra-acetic acid) at $100 \mathrm{~V}$ for 90 minutes. In some cases PCR product was analysed on $10 \%$ polyacrylamide gels and electrophoresed at $250 \mathrm{~V}$ for 1.5 hours. The gel was stained with $0.5 \mu \mathrm{g} / \mathrm{ml}$ ethidium bromide in water. The DNA was visualized under short wavelength ultraviolet light.

\section{Results}

The sensitivity of the above PCR protocol for detection of small cell numbers was determined by testing a series of cell suspensions of Nalm6 cells containing $10^{3}, 10^{2}$ and 10 cells in Hanks's solution. A monoclonal band was observed in all cases. In lymph node aspirates the monoclonal cell population will often be mixed with other cell types. Suspensions of U266 cells were mixed with human peripheral blood lymphocytes in proportions ranging from 10 to $100 \%$ U266 cells, in a total number of $10^{4}$ cells. It was possible to detect U266 cells when present at $10 \%$ or greater, although the PCR protocol gave a very faint band on agarose gels at $10 \%$ (fig 1 , lanes $1-7$ ).

To estimate the stability of lymphoid cells in Hanks's solution, Nalm6 cell suspensions of $10^{5}, 10^{4}$ and $10^{3}$ cells $/ \mathrm{ml}$ were prepared and stored at $4^{\circ} \mathrm{C}$. DNA was extracted from $100 \mu \mathrm{l}$ of each cell suspension at time zero and then at 24 hour intervals up to 4 days. A tenth of the DNA sample from all these time-points was subjected to PCR (equivalent to DNA from 10, $10^{2}$, and $10^{3}$ cells, fig 2 ). A monoclonal band was detected for all samples up to 3 days storage, but the bands were weaker for DNA from cell numbers less than $10^{3}$ at three days. A weak band was detected after 4 days storage only for the DNA sample equivalent to $10^{3}$ original cells. After 24 hours storage, the monoclonal Nalm6 PCR product was still clearly visible but a background smear of PCR products was also present, perhaps due to partial degradation in the sample.

Examples of PCR results for lymph node aspirates are also presented in fig 1, lanes 8-16. Lanes 8-10 show a discrete monoclonal band (100-120 base pairs) of amplified DNA observed in three cases of B-NHL; lanes 11-13 show failure of amplification or the broad smear of polyclonal amplified DNA observed in three cases of metastatic carcinoma in lymph node aspirate samples. Lanes 14-16 show the broad smear of polyclonal amplified DNA observed in three cases of reactive hyperproliferative lymph node aspirates.

Occasionally results could not be obtained on samples due to the presence of contaminating bands in the controls. These contaminating bands were not always present in the lymph 


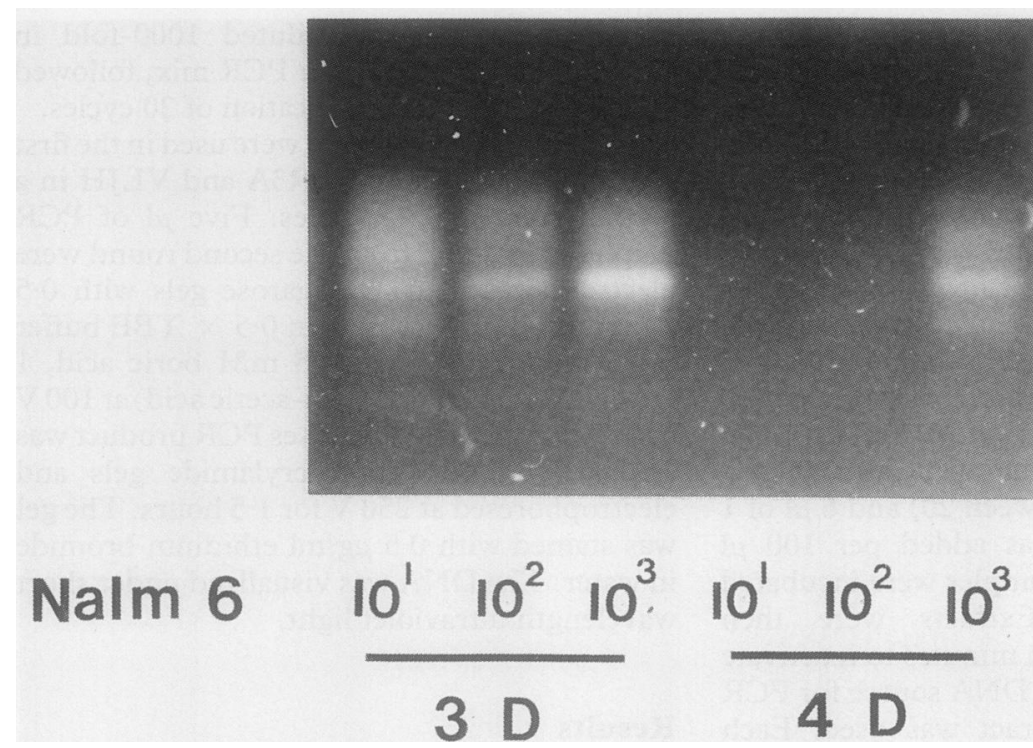

Figure 2 Stability of Nalm6 cells in Hanks's solution. DNA amplified from 10, $10^{2}$, and $10^{3}$ Nalm6 cells after storage for 3 and 4 days (D) at $4^{\circ} \mathrm{C}$.

node sample PCR product or if present were not of the same size. When such bands were found in the control the lymph node aspirate sample was not included in this study.

The sensitivity of the PCR protocol was studied further by making fivefold limiting dilutions of normal peripheral blood lymphocyte DNA, which were subjected to the PCR protocol above. The PCR products were then analysed on a polyacrylamide gel (fig 3 ). The number of PCR targets was estimated from the DNA concentration, based on $6 \mathrm{pg}$ of DNA/diploid cell, ${ }^{9}$ an estimate of $80 \%$ for the percentage of lymphocytes isolated by Ficoll

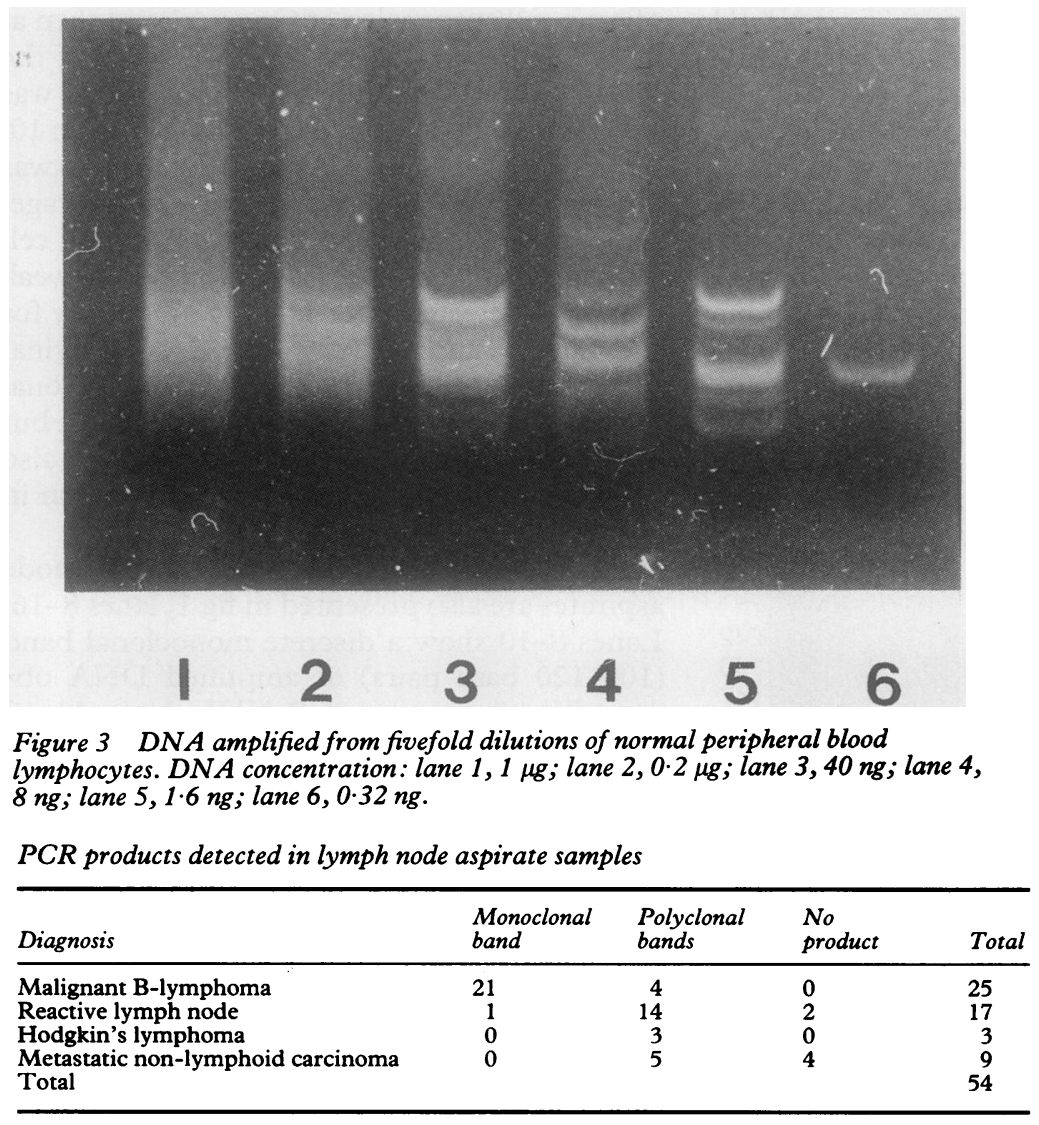

gradient centrifugation, and an estimate of $15 \%$ of the percentage of lymphocytes which are B lymphocytes. Polyclonal bands were obtained when the amount of DNA added to the PCR was $40 \mathrm{ng}$ ( 800 targets) or higher. For dilutions containing $8 \mathrm{ng}$ (160 targets) and $1.6 \mathrm{ng}$ (32 targets) oligoclonal bands were obtained. A monoclonal band was detected when an average of $0.32 \mathrm{ng}$ (6 targets) was added to the PCR. Fifteen replicates of a dilution containing an average of $0.06 \mathrm{ng}$ (about one target) underwent PCR and monoclonal bands (between one and three distinct bands) were detected in 11 tubes and the other four samples were negative. This suggests that approximately one IgH molecule can be detected by PCR. The results for 54 lymph node aspirates are summarised in the table. Most samples were tested in at least two separate experiments. In a few cases only one experiment was performed due to low cell numbers. Twenty-one malignant B-cell lymphoma samples gave discrete monoclonal bands. More than one monoclonal band was observed in five of the 21 samples, four samples gave two discrete bands, and one sample gave three discrete bands. The other four cases of malignant B-lymphoma produced a diffuse polyclonal smear. Of 17 reactive lymph node samples one case gave two discrete bands and the others were polyclonal or gave no PCR product. A diffuse polyclonal smear was also seen in the three Hodgkin's lymphoma samples and a polyclonal smear or no product was observed with metastatic carcinoma lymph node samples.

Based on these results the sensitivity of diagnosis for malignant $\mathrm{B}$ lymphoma was $84 \%$ and the specificity of diagnosis was $96 \cdot 6 \%$.

\section{Discussion}

The PCR method described generated amplification from as few as 10 Nalm 6 cells in the absence of competing templates. Cell mixing experiments suggest that in order to be detected the clone must comprise approximately $10 \%$ or greater of the total number of cells in the aspirate sample. The estimation of stability of lymphoid samples in Hanks's solution indicated that a result can be obtained from an aspirate sample kept at $4^{\circ} \mathrm{C}$ even after 3 days. It is advisable to process the lymph node aspirate samples within 24 hours of receipt especially if samples contain very few cells. We have obtained positive results from lymph node aspirate samples that have been stored for up to 48 hours.

A monoclonal gene rearrangement was not detected in four of 25 cases of B lymphoma, a phenomenon noted previously. ${ }^{23}$ This could be explained by an unusual rearrangement or sequence of the Ig genes which is not recognized by the consensus primers used in this study. Immunophenotypic studies indicated a probable $T$ cell origin for one of these patients. The phenomenon could also be explained if the percentage of lymphoma cells was lower than $10 \%$ against a background of normal lymphocytes. 
Of the 17 cases of reactive hyperplasia, one case showed monoclonal bands. The clinical features in this case suggested infection. Histopathology was not performed and the patient has remained well during the 12 months following node aspiration. Monoclonality in this sample could have resulted from contamination or from sampling of a localized reactive clone of lymphocytes within the node. An alternative explanation is that a low starting number of polyclonal lymphocytes resulted in PCR amplification being initiated from two templates. It is important to note that the same two bands were obtained in this sample on separate occasions. Our limiting dilution experiments suggest that when the starting DNA concentration is very low there is preferential amplification of some Ig genes so that one or a few monoclonal bands may be detected in polyclonal DNA. We now routinely process all samples in duplicate and it is our experience that for samples of low DNA concentration different sized bands are obtained from duplicates of samples, which are presumably polyclonal.

The utmost precaution was taken to prevent contamination as outlined by Kwok et al ${ }^{10}$ and a negative control was carried through the entire DNA extraction and PCR protocol for each sample. The lymph node aspirate sample was divided into two separate samples in the early stages of processing as an added precaution to provide a back up sample. The negative controls were devoid of PCR product for all the samples in the table.

The absence of product in some reactive lymph nodes or nodes infiltrated by carcinoma could have been due to low cell number or to inefficient amplification. A greater number of cell cycles could have been used to increase sensitivity, but we have found that this often produces an increase in non-specific bands.

Detection of monoclonality by PCR can complement present cytological and immunological methods for the study of node aspirates. The technique is simple and interpretation of the result is reduced to the presence or absence of a monoclonal band on an agarose gel. There are however a number of limitations. A sufficient number of lymphocytes must be obtained so that a heterogeneous amplified product will be obtained if a polyclonal population is present; contamination must be avoided; the neoplastic population must comprise $10 \%$ or more of the total population; and the gene rearrangement of the neoplastic clone must be amplifiable by the primers used. It seems advisable to study in parallel two samples of the node aspirate and to place more weight on the presence rather than absence of a monoclonal band.

This study was funded by the National Health and Medical Research Council and by the Anti-Cancer Foundation of the Universities of South Australia.

1 Orell SR, Sterrett GF, Walters MNI, Whitaker D. Manual and atlas of fine needle aspiration cytology. Edinburgh Churchill Livingstone, 1986:1-2

2 Trainor KJ, Brisco MJ, Story CJ, Morley AA. Monoclonality on B-lymphoproliferative disorders detected at the DNA level. Blood 1990;75:2220-2.

3 Wan JH, Trainor KJ, Brisco MJ, Morley AA. Monoclonality in B cell lymphoma detected in paraffin wax embedded sections using the polymerase chain reaction. $J$ Clin Pathol 1990;43:888-90.

4 Campana D, Janossy G, Bofill M, et al. Human B cell development I. Phenotypic differences of B lymphocytes in the bone marrow and peripheral lymphoid tissue. in the bone marrow and $\mathrm{p}$

5 Nilsson K, Bennich H, Johansson SG, Ponten J. Established immunoglobulin producing myeloma (IgE) and lymphoblastoid (IgG) cell lines from an IgE myeloma patient. Clin Exp Immunol 1970;7:477-89.

6 Higuchi $R$. Simple and rapid preparation of samples from PCR. In: Erlich HA, ed. PCR technology. New York Stockton Press, 1989:31.

7 Cleary ML, Chao J, Warnke R, Sklar J. Immunoglobulin gene rearrangement as a diagnostic criterion of $\mathrm{B}$-cell lymphoma. Proc Natl Acad Sci USA 1984;81:593-7.

8 Brisco MJ, Tan LW, Orsborn A, Morley AA. Development of a highly sensitive assay, based on the polymerase chain reaction, for rare B-lymphocyte clones in a polyclonal reaction, for rare B-lymphocyte clones in

9 Jeffreys A, Wilson V, Neumann R, Keyte J. Amplification of human minisatellites by the polymerase chain reaction: human minisatellites by the polymerase chain reaction: Towards DNA fingerp

$10 \mathrm{Kwok}$ S, Higuchi R. Avoiding false positives with PCR. Nature 1989;339:237-8. 


\section{Corrections}

Combined immunohistochemical and immunofluorescence method to determine the phenotype of proliferating cell populations (A L Ramshaw, D V Parums: $f$ Clin Pathol 1992;45:1015-17).

The colour photographs below were inadvertently transposed during the printing process: this is how they should have appeared.

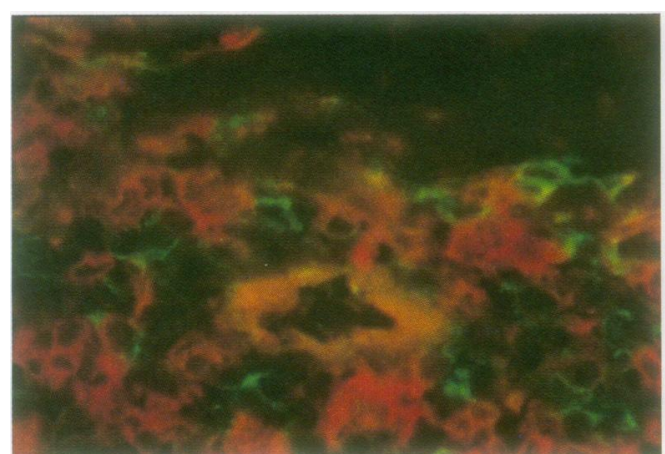

Figure 1 Section of an atherosclerotic abdominal aortic aneurysm showing the chronically inflamed adventitia ('chronic periaortitis'). Double immunostaining has been performed with TAL.1B5 (HLA-DRa) using the APAAP stain (red) and with $\mathcal{F C} 70$ (CD31) with indirect staining using FITC conjugated antibodies (green). In the centre of the figure is a vasa vasorum showing double staining (yellow) of the endothelium which is positive for both $C D 31$ (green) and $H L A-D R a$ (red).

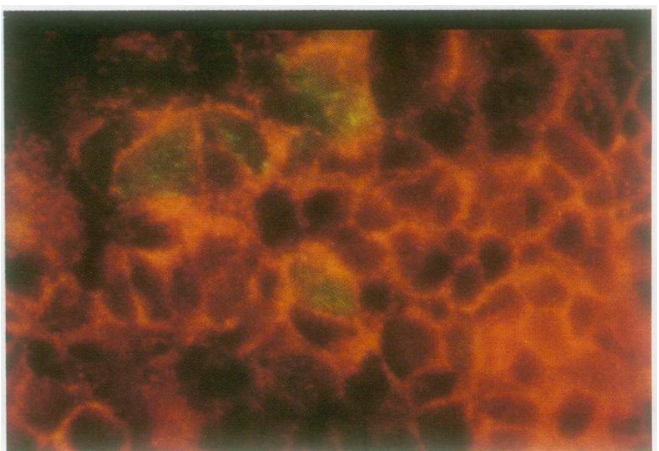

Figure 2 The periphery of a lymphoid follicle within the aortic adventitia from a section of an atherosclerotic aortic aneurysm. Double immunostaining has been performed with T3-10 (CD4) using the APAAP stain (red) and with Ki-67 (proliferation marker) with indirect staining using FITC conjugated antibodies (green). Ki-67 positive (green) staining is present within CD4 positive

(red/orange) cells indicating that cells associated with the T-helper phenotype are proliferating.

A rapid method for the detection of monoclonality in B cell lymphoma in lymph node aspirates using the polymerase chain reaction (P J Sykes, et al: $\mathcal{f}$ Clin Pathol 1992;45:420-3)

A typographical error appeared in the sequence of the FR3A primer in the methods section of the above paper:

It was published as:

FR3A, 5' ACACG G[C/T][G/C] TGTATT ACTGT 3'

It should read:

FR3A, 5' ACACG GC[C/T][G/C] TGTATT ACTGT 3'

NOTICES

\section{Third Congress of Asia Pacific \\ Association of Societies of Pathologists}

14-17 February 1993

At present, the member countries of APASP are Bangladesh, India, Pakistan, Mayanmar, Nepal, New Zealand, Australia and Singapore. Korea, Japan, and Malaysia are the observing countries.

A detailed scientific programme has been chalked out for this congress. There will be three symposia: (a) postgraduate medical education in pathology/laboratory medicine in the developing countries, (b) epidemiology, diagnosis, and prevention of AIDS and (c) cancer control programmes in developing countries. There will be two workshops: the laboratory diagnosis of Kala-azar and on FNAC (fine needle aspiration cytology).

There will be four free paper sessions. Among others, papers on viral hepatitis, tropical diseases including malaria and sexually transmitted diseases apart from AIDS, will be preferred.

Medical professionals from all branches of pathology who wish to participate in this congress are requested to contact directly the secretariat of Third APASP Congress, in the Department of Pathology, Institute of Postgraduate Medicine and Research (PGMR), Dhaka-1000, Bangladesh.

\section{Histopathology for the MRCPath 25-29 January 1993, Oak Hotel, Brighton}

A 5 day intensive residential course for MRCPath candidates will include tuition on general pathology, histopathology, cytopathology, necropsy pathology and other subspecialty areas. The course is organised by the South East Thames Regional Higher Training Committee.

Speakers will include Dr M G Cook, Guildford, Professor PA Hall, St. Thomas's Hospital, Professor N Gibbs, Guildford, Dr S Humphreys, King's College, Dr N Kirkham, Brighton, Professor D Levison, Guy's Hospital, Dr S Lucas, UCHMSM, Dr J Salisbury, King's College.

The course will form the first part of a three year cycle aimed to provide a comprehensive preparation for the MRCPath examination in histopathology.

The registration fee of $£ 375$ includes full accommodation and catering for five days and nights.

For registration, contact: Mrs P Newland, Histopathology Department, Royal Sussex County Hospital, Brighton BN2 5BE. Telephone 0273-696955 extension 4269. Fax 0273-600182.

\section{Call for pathologists}

The South African Institute for Medical Research has vacancies for anatomical pathologists (histopathologists) in its diagnostic service.

The South African Institute for Medical Research is a non-profit and non-government organisation which, in addition to its research and training functions, provides a diagnostic pathology and laboratory medicine service across most of South Africa.

Applicants should be in possession of a medical qualification registrable with the South African Medical and Dental Council, and have a qualification and experience in anatomical pathology.

An ability to communicate effectively in both written and spoken English is essential.

Salary and conditions of service are negotiable, depending on qualifications and experience.

Applications, which should include a curriculum vitae and the names of three referees, should be addressed to Miss Joy Paige, Human Resources Manager, SAIMR, PO Box 1038 , 2000 Johannesburg, South Africa.

Further information about the positions can be obtained from Miss Paige or Dr Doehring at the above address or: telephone $+2711725-0511$, or fax $+2711725-5891$.

\section{ACP Locum Bureau}

The Association of Clinical Pathologists runs a locum bureau for consultant pathologists.

Applicants with the MRCPath who would like to do locums and anyone requiring a locum should contact The General Secretary, 221 Preston Road, Brighton BN1 6SA. Tel: (0273) 561188. Fax: (0273) 541227. 